\title{
Maternal and fetal outcome of Placenta Previa at a tertiary centre in North Kerala, India
}

\section{Mohammed Sidhiq C.*}

Department of Obstetrics and Gynecology, Government Medical College, Kozhikode, Kerala, India

Received: 12 March 2018

Accepted: 20 March 2018

\section{*Correspondence:}

Dr. Mohammed Sidhiq C.,

E-mail: cmsidhiq@gmail.com

Copyright: (C) the author(s), publisher and licensee Medip Academy. This is an open-access article distributed under the terms of the Creative Commons Attribution Non-Commercial License, which permits unrestricted non-commercial use, distribution, and reproduction in any medium, provided the original work is properly cited.

\begin{abstract}
Background: Placenta previa is defined as placenta that is implanted somewhere in the lower uterine segment either over or very near the internal cervical os. Placenta previa and coexistent accrete syndromes contribute substantively to maternal and perinatal morbidity and mortality.

Methods: This study was conducted in the Department of Obstetrics and Gynaecology during the period from June 2016 to May 2017 including antenatal patients of 24 weeks of gestation regardless of their parity. They would be selected from the same O.P day as that of case in a 1:4 case: control manner. Statistical analysis was done using SPSS version 16.0 for Windows.

Results: Age, booking status, Gestational age at delivery and gravidity was comparable between the two groups. The risk for placenta praevia was more among patients with a previous history of CS. Risk for antepartum bleeding was significantly higher among cases of placenta praevia. CS rate and proportion of patients who required blood transfusion was significantly high among cases. Intraoperative and postoperative complications were significantly higher among cases. There was no significant difference in neonatal death rate and NICU admission rate between the two groups.

Conclusions: Incidence of placenta previa is $0.78 \%$. There is significant association with placenta previa and maternal morbidity, first trimester and second trimester bleeding increased blood transfusions, need for caesarean section, prolonged hospital stay, previous caesarean section, previous dilatation and curettage, placenta accreta, postoperative complications and NICU admission. Measures to reduce the primary caesarean section rate should be adopted.
\end{abstract}

Keywords: Antepartum hemorrhage, Maternal morbity, Placenta previa

\section{INTRODUCTION}

Placenta previa is defined as placenta that is implanted somewhere in the lower uterine segment either over or very near the internal cervical os. It occurs in $2.8 / 1000$ singleton pregnancies and 3.9/1000 twin pregnancies. ${ }^{1}$ The incidence of hysterectomy after caesarean section (CS) for placenta previa is $5.3 \%$ (relative risk compared with those undergoing CS without placenta previa in 33$){ }^{2}$ Perinatal mortality rates are three or four times higher than in normal pregnancies.,
The classification of placenta previa includes

- Low-lying- placenta positioned to within $5 \mathrm{~cm}$ of the OS

- Marginal-placenta previa- located at the margin of the OS

- $\quad$ Partial placenta previa- placenta partially covering the internal OS

- Total placenta previa- placenta completely covering the OS 
- $\quad$ Risk factors include Maternal age, multiparity, prior caesarean delivery, elevated prenatal screening MSAFP levels and previous abortion

Painless bleeding is the most characteristics event with placenta previa. ${ }^{5}$ Bleeding from a previa usually begins without warning and without pain or contractions in a woman who has had an uneventful prenatal course. Usually it ceases, only to recur.

Placenta accrete syndrome include any placental implantation with abnormally firm adherence to myometrium because of partial or total absence of decidua basalis and imperfect development of fibrinoid. The most common indication for peripartum hysterectomy was placenta accreta-48.4\%, incidence of placenta previa accreta account for 32.3 percent of all indications. ${ }^{6}$

The majority of cases of placenta previa are diagnosed during routine sonography, a trans-vaginal approach is adequate in revealing the position.

Management strategies are based on:

- The maternal condition and amount of hemorrhage

- Fetal condition (gestational age and expected birth weight)

- Neonatal Facilities

- Management of patients with bleeding

Women who present with bleeding in the second half of pregnancy should have a sonographic examination for placental location prior to any attempt to perform a digital examination. ${ }^{6}$

It is reasonable to hospitalize women with placenta previa while they are having an acute bleeding episode or uterine contractions. The blood bank must be capable of making available at least 4 units of compatible packed red blood cells and coagulation factors at short notice. Rh immune globulin should be administered to Rh-negative women. Steroids should be administered in women between 24 and 34 weeks of gestation. In women with history of cesarean delivery or uterine surgery, detailed sonography should be performed to exclude placenta accrete. $^{7}$

When the patient has had no further bleeding for 48 hours, she may be considered for discharge. In patients with severe, acute third-trimester bleeding, an efficient management plan including life-support measures and immediate operative intervention are required.

Management includes constant observation and monitoring, administration of intravenous fluids, transfusion therapy, assessment of renal function and intravascular status, assessment of the fetus, and delivery. ${ }^{8}$
In a patient with moderate bleeding, delivery by cesarean section should be performed if the pregnancy is 36 weeks and more. If the fetal lungs are immature, intensive monitoring in the labour and delivery unit for a period of 24 to 48 hours.

Most patient with placenta previa and moderate bleeding stop bleeding, thereby becoming candidates for expectant management. However, premature rupture of the membranes, other maternal medical conditions, or fetal distress may make continuation of pregnancy inappropriate.

Immediate delivery of mature foetuses is the appropriate course, regardless of the minor degree of bleeding. If the fetal lungs are immature and gestational age is less than 36 weeks, the patient with mild bleeding also becomes a candidate for expectant management.

\section{Expectant Management}

It was pioneered in Belfast by Macafee and Johnson et al. The rationale of expectant management is that the bleeding episode is usually self-limiting and not fatal in the absence of inciting trauma. In carefully controlled conditions the delivery of the fetus can be safely delayed, till maturity is achieved. Ultrasound examination should be performed to determine gestational age, fetal number, fetal position and estimated fetal weight. ${ }^{9}$

\section{Mode of Delivery}

Women in whom the distance between the lower placental edge and the internal cervical os was greater than $2 \mathrm{~cm}$ could safely have a vaginal delivery. In women with a placenta-internal os distance less than $2 \mathrm{~cm}$, majority required cesarean delivery, usually for bleeding. Studies suggest that women with placenta previa should have a trans-vaginal sonogram in the late third trimester, and those with a placental edge to internal os distance of less than $2 \mathrm{~cm}$ should be delivered by cesarean. Women whose placentas are $2 \mathrm{~cm}$ or more from the os undergo a normal labour. ${ }^{10}$

When there is an anterior placenta previa, there is a considerable likelihood of incising through the placenta during delivery leading to significant maternal and fetal blood loss and also to difficulty with delivery. Avoid incision into the placenta.

Following placenta removal,when hemostasis at the placental implantation site cannot be obtained by pressure, the implantation site can be over sewn with 0 chromic sutures.

Cho and associates (1991) described interrupted 0chromic sutures at $1 \mathrm{~cm}$ intervals to form a circle around the bleeding position of the lower segment to control hemorrhage. In a stable patient, it is reasonable to perform a cesarean delivery at 36-37 weeks of gestation, 
after documentation of fetal lung maturity by amniocentesis. ${ }^{11}$

\section{Anaesthesia for delivery}

In the past, it was generally recommended that cesarean deliveries for placenta previa be performed under general anesthetic. It was believed that this allowed more controlled surgery.

\section{Maternal and Perinatal Outcomes}

Placenta previa and coexistent accrete sydromes both contribute substantively to maternal morbidity and mortality. ${ }^{12}$ In one review, there was a three-fold increased maternal mortality ratio of 30 per 100000 for women with previa (oyelese, 2006).

Preterrn delivery. continues to be a cause for perinatal death. In a retrospective cohort study there was a higher rate of preterrn births, but no difference in birth weights after controlling for gestational age at delivery.

A retrospective cohort study performed of live birth in united states showed that placenta previa was recorded in 2.8/1000 live births. Neonatal mortality rate was 0.7 with previa, compared with 2.5/ 1000 among other pregnancies. ${ }^{13}$ Mortality rates for term babies were higher among babies born to women with placenta previa, than among babies born to women without placenta previa.

Among preterm births, however, placenta previa was not associated with increased neonatal mortality by fetal growth centiles. This shows that pregnancies that are diagnosed with placenta previa must be monitored carefully, especially, as they approach term. ${ }^{14}$

\section{METHODS}

This study was conducted in the Department of Obstetrics and Gynaecology during the period from June 2016 to May 2017.

\section{Inclusion criteria}

- All antenatal patients of 24 weeks of gestation regardless of their parity.

- Consecutive patients who satisfy the inclusion criteria and have diagnosed to have low lying placenta in their mid-trimester scanning will be taken as cases.

- Consecutive patients who satisfy inclusion criteria and have no low-lying placenta but similar to that of cases in age, parity, gestational age within +2 weeks, will be taken as controls. They would be selected from the same O.P day as that of case in a 1:4 case: control manner.

- Variables under study

- Previous Abortion Evacuation.

- Previous Dilatation and Curettage.
- Previous Caesarean Section

- $\quad$ Previous history of Manual removal of placenta.

\section{Statistical analysis}

Statistical analysis was done using SPSS version 16.0 for Windows. Data was expressed as frequencies and percentages. Chi square test and Fisher's exact test was used to analyses the data. Risk for placenta praevia was estimated by odds ratio (OR) and risk for developing various outcomes was expressed as relative risk (RR). 95\% confidence interval for the same was also estimated. A $p$ value $<0.05$ was considered to be statistically significant.

\section{RESULTS}

The study was conducted in Govt. Medical College, Kozhikode during the period of one year from June 2016 to May 2017. During this period, total numbers of deliveries were 15604 and total numbers of placenta previa cases were 122 . So, incidence of placenta previa is $0.78 \%$. Age was comparable between the two groups, $\Psi^{2}(2)=2.648, \mathrm{p}=0.266($ Table 1$)$.

Table 1: Age distribution.

\begin{tabular}{|c|c|c|c|c|}
\hline \multirow{2}{*}{ Group } & \multicolumn{3}{|c|}{ Age (year) } & \multirow{2}{*}{ Total } \\
\hline & $<20$ & $20-35$ & $\geq 35$ & \\
\hline Case & $2(2.9 \%)$ & $62(91.2 \%)$ & $\overline{4}(5.9 \%)$ & $68(100 \%)$ \\
\hline Control & $10(5.5 \%)$ & $151(83 \%)$ & $\begin{array}{l}21 \\
(11.5 \%)\end{array}$ & $182(100 \%)$ \\
\hline Total & $12(4.8 \%)$ & $213(85.2 \%)$ & $25(10 \%)$ & $250(100)$ \\
\hline
\end{tabular}

Booking status was comparable between the two groups. $\Psi^{2}(1)=1.553, p=0.213$. Gestational age at delivery was comparable between the two groups, $\Psi^{2}(2)=3.381, p$ $=0.184($ Table 2$)$.

Table 2: Gestational age at delivery.

\begin{tabular}{|lllll|}
\hline \multirow{5}{*}{ Group } & $\begin{array}{l}\text { Gestational age at delivery } \\
\text { weeks }\end{array}$ & $\begin{array}{l}\mathbf{3 1 - 3 6} \\
\text { weeks }\end{array}$ & $\begin{array}{l}\mathbf{2 3 7} \\
\text { years }\end{array}$ & Total \\
& weal & 13 & 53 & 68 \\
Case & 2 & 13 & $(77.9 \%)$ & $(100 \%)$ \\
\hline \multirow{2}{*}{ Control } & 5 & $19.1 \%)$ & 158 & 182 \\
& $(2.7 \%)$ & $(10.4 \%)$ & $(86.8 \%)$ & $(100 \%)$ \\
\hline \multirow{2}{*}{ Total } & 7 & 32 & 211 & 250 \\
& $(2.8 \%)$ & $(12.8 \%)$ & $(84.4 \%)$ & $(100 \%)$ \\
\hline
\end{tabular}

There was no significant difference between the groups with respect to gravidity, $\Psi^{2}(3)=1.093, p=0.779$. There was no significant difference between the groups with respect to parity, $\Psi^{2}(3)=2.387, \mathrm{p}=0.496$ (Table 3 ). There was no significant difference between the groups with respect to h/o abortions, $\Psi^{2}(2)=0.341, \mathrm{p}=0.843$. 
The risk for placenta praevia was more among patients with a previous history of $\mathrm{CS}, \mathrm{OR}=2.14(1.14-3.99)$, $\Psi^{2}(1)=5.85, p=0.016$. The risk for placenta praevia was more among patients with a previous history of $\mathrm{D} \& \mathrm{C}$ but was not statistically significant, $\mathrm{OR}=1.33 \quad(0.67-$ 2.63), $\Psi^{2}(1)=0.795, \mathrm{p}=0.372$.

Table 3: Parity distribution.

\begin{tabular}{|llllll|}
\hline Group & Parity & $\mathbf{1}$ & $\mathbf{2}$ & $\mathbf{3}$ & Total \\
\hline Case & $\mathbf{0}$ & $25(36.8 \%)$ & $16(23.5 \%)$ & $4(5.9 \%)$ & $68(100 \%)$ \\
\hline Control & $23(33.8 \%)$ & $72(39.6 \%)$ & $34(18.7 \%)$ & $5(2.7 \%)$ & $182(100 \%)$ \\
\hline Total & $71(39 \%)$ & $97(38.8 \%)$ & $50(20 \%)$ & $9(3.6 \%)$ & $250(100 \%)$ \\
\hline
\end{tabular}

Risk for antepartum bleeding was significantly higher among cases of placenta praevia, $\mathrm{RR}=9.15(5.41-15.47)$, $\Psi^{2}(1)=113.58, \mathrm{p}=<0.00001$ (Table 4).

Table 4: Presenting complaints.

\begin{tabular}{|lllll|}
\hline Group & Bleeding & $\begin{array}{l}\text { Plood } \\
\text { stained } \\
\text { discharge }\end{array}$ & Nil & Total \\
\hline Case & 52 & 9 & 7 & 68 \\
\hline Control & $(76.5 \%)$ & $(13.2 \%)$ & $(10.3 \%)$ & $(100 \%)$ \\
\hline Total & $(7.1 \%)$ & $(25.8 \%)$ & $(67 \%)$ & $(100 \%)$ \\
\hline & $(26 \%)$ & $(22.4 \%)$ & $(51.6 \%)$ & $(100 \%)$ \\
\hline
\end{tabular}

The risk for I trimester bleed was more among placenta praevia patients, $\mathrm{RR}=5.83(3.53-9.63), \Psi^{2}(1)=59.38, \mathrm{p}$ $=<0.00001$. The risk for II trimester bleed was more among placenta praevia patients, $\mathrm{RR}=44.61$ (14.39138.27), $\Psi^{2}(1)=153.11, \mathrm{p}=<0.00001$.

The risk for pallor was more among placenta praevia patients, $\mathrm{RR}=3.41(2.1-5.53), \quad \Psi^{2}(1)=26.18$, $\mathrm{p}=<0.00001$. Most of the cases were of central placenta praevia completely covering the OS (Table 5).

Table 5: Placental edge from OS.

\begin{tabular}{|c|c|c|c|c|}
\hline \multirow[b]{2}{*}{ Group } & \multicolumn{3}{|c|}{ Placental edge from OS } & \multirow[b]{2}{*}{ Total } \\
\hline & $<2 \mathrm{~cm}$ & $\geq 2 \mathrm{~cm}$ & $\begin{array}{l}\text { Covering } \\
\text { OS }\end{array}$ & \\
\hline Case & $\begin{array}{l}28 \\
(41.2 \%)\end{array}$ & $\begin{array}{l}10 \\
(14.7 \%)\end{array}$ & $\begin{array}{l}30 \\
(44.1 \%)\end{array}$ & $\begin{array}{l}68 \\
(100 \%)\end{array}$ \\
\hline Control & $6(3.3 \%)$ & $\begin{array}{l}176 \\
(96.7 \%)\end{array}$ & 0 & $\begin{array}{l}182 \\
(100 \%)\end{array}$ \\
\hline Total & $\begin{array}{l}34 \\
(13.6 \%)\end{array}$ & $\begin{array}{l}186 \\
(74.4 \%)\end{array}$ & $\begin{array}{l}30 \\
(12 \%)\end{array}$ & $\begin{array}{l}250 \\
(100 \%)\end{array}$ \\
\hline
\end{tabular}

CS rate was significantly high among cases, $R R=1.65$ (1.32-2.05), $\Psi^{2}(1)=16.31, \mathrm{p}=<0.00001$ (Table 6).

The incidence of placenta accreta was significantly higher among cases, RR=14.72 (3.35-64.71), Fisher's exact test $\mathrm{p}=<0.0001$. (Table 7). Proportion of patients who required blood transfusion was significantly higher among cases. (Table 8).

Table 6: Mode of delivery.

\begin{tabular}{|c|c|c|c|c|}
\hline \multirow[b]{2}{*}{ Group } & \multicolumn{3}{|c|}{ Mode of delivery } & \multirow[b]{2}{*}{ Total } \\
\hline & $\begin{array}{l}\text { Spontaneous } \\
\text { vaginal } \\
\text { delivery }\end{array}$ & CS & $\begin{array}{l}\text { Instrumental } \\
\text { delivery }\end{array}$ & \\
\hline Case & $\begin{array}{l}17 \\
(25 \%)\end{array}$ & $\begin{array}{l}49 \\
(72.1 \%)\end{array}$ & $\begin{array}{l}2 \\
(2.9 \%)\end{array}$ & $\begin{array}{l}68 \\
(100 \%)\end{array}$ \\
\hline Control & $\begin{array}{l}95 \\
(52.2 \%)\end{array}$ & $\begin{array}{l}78 \\
(42.9 \%)\end{array}$ & $\begin{array}{l}9 \\
(4.9 \%)\end{array}$ & $\begin{array}{l}182 \\
(100 \%)\end{array}$ \\
\hline Total & $\begin{array}{l}112 \\
(44.8 \%)\end{array}$ & $\begin{array}{l}127 \\
(50.8 \%)\end{array}$ & $\begin{array}{l}11 \\
(4.4 \%)\end{array}$ & $\begin{array}{l}250 \\
(100 \%)\end{array}$ \\
\hline
\end{tabular}

Overall (antepartum/ intrapartum/ postpartum): $\mathrm{RR}=$ $6.14 \quad(3.74-10.09), \quad \Psi^{2}(1)=65.65, \quad \mathrm{p}=<0.00001$. Antepartum: $\quad \mathrm{RR}=9.72 \quad(4-23.59), \quad \Psi^{2}(1)=37.14$, $\mathrm{p}=<0.00001$. Intra/ postpartum: $\mathrm{RR}=7.25$ (3.8-13.8), $\Psi^{2}(1)=47.93, \mathrm{p}=<0.00001$. Intraoperative complications were significantly higher among cases (Table 9).

Table 7: Incidence of placenta accrete.

\begin{tabular}{|lll|l|}
\hline Group & \multicolumn{2}{l}{$\begin{array}{l}\text { Presence of adherent } \\
\text { placenta }\end{array}$} & Total \\
& No & Yes & \\
\hline Case & $57(83.8 \%)$ & $11(16.2 \%)$ & $68(100 \%)$ \\
\hline Control & $180(98.9 \%)$ & $2(1.1 \%)$ & $182(100 \%)$ \\
\hline Total & $237(94.8 \%)$ & $13(5.2 \%)$ & $250(100 \%)$ \\
\hline
\end{tabular}

Table 8: Blood tranfusion incidence.

\begin{tabular}{|lllll|}
\hline Group & Blood transfusion & & \\
& No & $\begin{array}{l}\text { Antepartu } \\
\text { m }\end{array}$ & $\begin{array}{l}\text { Intra/pos } \\
\text { tpartum }\end{array}$ & Total \\
\hline Case & 29 & 15 & 24 & 68 \\
& $(42.6 \%)$ & $(22.1 \%)$ & $(35.3 \%)$ & $(100 \%)$ \\
\hline \multirow{2}{*}{ Control } & 165 & 6 & 11 & 182 \\
& $(90.7 \%)$ & $(3.3 \%)$ & $(6.0 \%)$ & $(100 \%)$ \\
\hline \multirow{2}{*}{ Total } & 194 & 21 & 35 & 250 \\
& $(77.6 \%)$ & $(8.4 \%)$ & $(14.0 \%)$ & $(100 \%)$ \\
\hline
\end{tabular}


Table 9: Intraoperative complications.

\begin{tabular}{|lllll|}
\hline Group & \multicolumn{2}{l}{ Intraoperative complications } & Total \\
& Nil & Bleeding & Hypotension & \\
\hline Case & 19 & 24 & 6 & 49 \\
& $(38.8 \%)$ & $(49 \%)$ & $(12.2 \%)$ & $(100 \%)$ \\
Control & 72 & 4 & 2 & 78 \\
& $(92.3 \%)$ & $(5.1 \%)$ & $(2.6 \%)$ & $(100 \%)$ \\
\multirow{2}{*}{ Total } & 91 & 28 & 8 & 127 \\
& $(71.7 \%)$ & $(22 \%)$ & $(6.3 \%)$ & $(100 \%)$ \\
\hline
\end{tabular}

Overall: $\mathrm{RR}=7.96(3.57-17.72), \Psi^{2}(1)=42.46, \mathrm{p}=$ <0.00001. Bleeding: $R R=10.6(3.94-28.55), \Psi^{2}(1)=39$, $\mathrm{p}=<0.00001$. Hypotension: $\mathrm{RR}=8.88 \quad(1.91-41.21)$, Fisher's exact test $p=0.003$. The risk for postoperative complications was significantly more among cases, $\mathrm{RR}=3.18$ (1.28-7.93), $\Psi^{2}(1)-6.98, \mathrm{p}=0.008$ (Table 10). There was no significant difference in 5, apgar score between the two groups, $\Psi^{2}(1)=1.921, \mathrm{p}=0.166$ (Table 11).

Table 10: Post operative complications.

\begin{tabular}{|llllll|}
\hline \multirow{2}{*}{ Group } & \multicolumn{2}{l}{ Postoperative complications } & & & \\
& Nil & PPH & Wound infection & Febrile morbidity & Total \\
\hline Case & $37(75.5 \%)$ & $6(12.2 \%)$ & $2(4.1 \%)$ & $4(8.2 \%)$ & $49(100 \%)$ \\
Control & $72(92.3 \%)$ & $5(6.4 \%)$ & $1(1.3 \%)$ & $0(0 \%)$ & $78(100 \%)$ \\
\hline Total & $109(85.8 \%)$ & $11(8.7 \%)$ & $3(2.4 \%)$ & $4(3.1 \%)$ & $127(100 \%)$ \\
\hline
\end{tabular}

Table 11: Apgar score.

\begin{tabular}{|llll|} 
Group & $\begin{array}{l}\text { Apgar at 5 } \\
\end{array}$ & \multicolumn{2}{l}{ Total } \\
\hline Case & $7(11.3 \%)$ & $\mathbf{2 5}(88.7 \%)$ & $62(100 \%)$ \\
\hline Control & $10(5.9 \%)$ & $159(94.1 \%)$ & $169(100 \%)$ \\
\hline Total & $17(7.4 \%)$ & $214(92.6 \%)$ & $231(100 \%)$ \\
\hline
\end{tabular}

There was no significant difference in neonatal death rate between the two groups, Fisher's exact test $p=0.337$. There was no significant difference in NICU admission rate between the two groups, $\Psi^{2}(1)=0.96, p=0.327$ (Table 12).

Table 12: Neonatal complications.

\begin{tabular}{|lll|}
\hline Group & NND & NICU admission \\
\hline Case & $4(6.5 \%)$ & $17(27.4 \%)$ \\
\hline Control & $6(3.6 \%)$ & $36(21.3 \%)$ \\
\hline Total & $10(4.3 \%)$ & $53(22.9 \%)$ \\
\hline
\end{tabular}

\section{DISCUSSION}

The total number of deliveries during the period was 15604 and the placenta previa cases were 122. Incidence of placenta previa cases was $0.78 \%$. The incidence is more in our hospital because it is a referral centre and so it would not reflect the general population.

Majority of patients are in the age group 20-35 and it is more in multi gravidae than in primi gravida. ${ }^{1} 42.6 \%$ patients had a history of prior caesarean section. Our study showed that the risk of placenta previa was more among patients with a previous history of $\operatorname{cs} 2$, with an OR of $2 .{ }^{14}$
$26.5 \%$ had a previous history of abortion which was comparable with that of controls. ${ }^{3}$ We didn't have any recurrence history in our study, but one study has shown that recurrence rate was $23 / 1000$ with an adjusted odds ratio of 9.74 . $27.9 \%$ of cases had a prior history of dilatation and curettage which shows that prior D \& $\mathrm{C}$ is a risk factor for placenta previa. ${ }^{5}$ In our study, first trimester bleeding was found in $54 \%$ cases and second trimester bleeding was found in $73 \%$ cases these patients were monitored closely as inpatients and more aggressively managed. ${ }^{6}$

In our study, $72 \%$ cases of placenta previa was delivered by caesarean section. Though our protocol is elective CS at 37 weeks, more than $50 \%$ of cases were emergency LSCS due to recurrent bleeding. ${ }^{7}$ Lesser degrees of previa had vaginal delivery. $2.9 \%$ had to be helped out by vacuum extraction.

There was no maternal death due to placenta previa neither in our study nor in our institution during the period due to any related cause of placenta previa. It is seen that the maternal mortality has decreased at a considerable level.

The improvement in antenatal diagnosis due to imaging techniques, easy availability of blood and blood products and expert management and timely intervention of care in tertiary centre has reduced the maternal mortality. Antepartum haemorrhage occurred in $76.5 \%$ of placenta previa cases in our study. ${ }^{8}$

Blood transfusion was given for $57 \%$ of patients with previa. Of these $22 \%$ was antepartum and $35 \%$ was in the intrapartum and postpartum period. A relative risk of 9.72 for antepartum transfusion and RR of 7.25 for intra / post-partum transfusion was seen this was in comparison 
with the study by Crane JM et al for maternal complications with placenta previa where the relative risk was 10.05 . Placenta accreta was found in $16.2 \%$ of the cases compared to $1.1 \%$ of the controls.

This incidence increased as the number of previous caesarean sections increased. Obstetric hysterectomy was done in two cases, as other operative procedures couldn't control the bleeding during caesarean section. Authors adopt a low threshold for hysterectomy in cases of placenta previa in order to minimize the blood loss and its sequelae.

Post-operative complications were seen in $24 \%$ of our cases whereas it was present in only about $7.7 \%$ of the controls. This is in comparison with the study by Sheiner $\mathrm{E}$ et al on the obstetric risk factors and pregnancy outcome in Soroka University Medical centre, Beersheva, Israel. ${ }^{8}$

The post-operative complications included postpartum haemorrhage, wound infections and febrile morbidity. ${ }^{9}$. Fetal growth restriction and preterm delivery was found in several studies including a population-based study by Anand $\mathrm{CV}$ et al, wherein approximately $12 \%$ of preterm delivery and $3.7 \%$ of growth restriction was attributed to placenta previa. In our study, this was comparable with the controls because our institution being a tertiary centre, we receive lots of referral from the hospitals in the periphery for want of better new born intensive care facilities. $^{10}$

There was no significant difference in the new born ICU admissions and neonatal demise in our study ${ }^{11}$. This may be attributed to the early and timely intervention in the way of elective caesarean sections. A population-based study to investigate risk factors and pregnancy outcome of patients with placenta previa by Rosenburg $\mathrm{T}$ et al showed placenta previa was not found as an independent risk factor for perinatal mortality (OR 1.018; 95\% CI 0.74-1.40, $\mathrm{p}=0.940)(\mathrm{b})$.

Incidence of placenta previa is $0.78 \%$. There is significant association with placenta previa and maternal morbidity. ${ }^{12}$ There is significant association of placenta previa with

First trimester and second trimester bleeding, increased blood transfusions, need for caesarean section. Prolonged hospital stays, previous caesarean section, previous dilatation and curettage, placenta accreta, postoperative complications and NICU admission. ${ }^{13}$

As dilatation and curettage is a significant risk factor in placenta praevia medical abortion should be promoted as and when recommended in place of dilatation and curettage. Previous caesarean sections have significant association with placenta previa hence the ceasarean section rate should be brought down. ${ }^{14}$ Measures to reduce the primary caesarean section rate should be adopted.

\section{ACKNOWLEDGMENTS}

Authors would like to acknowledge all the patients who have contributed to the study.

Funding: No funding sources

Conflict of interest: None declared

Ethical approval: The study was approved by the Institutional Ethics Committee

\section{REFERENCES}

1. Ananth CV, Demissie K, Smulian JC, Vintzileos AM. Placenta previa in singleton and twin births in the United States, 1989 through 1998: a comparison of risk factor profiles and associated conditions. Am J Obstet Gynecol. 2003;188(1):275-81.

2. Crane JM, Van den Hof MC, Dodds L, Armson BA, Liston R. Maternal complications with placenta previa. Am J Perinatol. 2000;17(2):101-5.

3. Crane JM, van den Hof MC, Dodds L, Armson BA, Liston R. Neonatal outcomes with placenta previa. Obstet Gynecol. 1999 177: 201-4.

4. Ananth CV, Smulian JC, Vintzileos AM. The effect of placenta previa on neonatal mortality: a population-based study in the United States, 1989 through 1997. Am J Obstet Gynecol. 2003;188(5):1299-304.

5. Obstetrical hemorrhage. In: Cunningham FG, MacDonald PC, Grant NF, Leveno KJ, Gilstrap LC, Hankins GDV et al. eds. Williams Obstetrics 20th ed. Norwalk, Conn: Appleton and Lang 1997; 74582.

6. Oppenheimer LW, Farine D, Ritchie JW, Lewinsky RM, Telford J, Fairbanks LA. What is a low-lying placenta? Am J Obstet Gynecol. 1991;165(41):1036-8.

7. Tuzović L, Djelmis J, Ilijić M. Obstetric risk factors associated with placenta previa development: casecontrol study. Croat Med J. 2003;44(6):728-33.

8. Sheiner E, Shoham-Vardi I, Hallak M, Hershkowitz R, Katz M, Mazor M. Placenta previa: obstetric risk factors and pregnancy outcome. J Matern Fetal Med. 2001;10(6):414-9.

9. Hung TH, Hsieh CC, Hsu JJ, Chiu TH, Lo LM, Hsieh TT. Risk factors for placenta previa in an Asian population. Int $\mathbf{J}$ Gynaecol Obstet. 2007;97(1):26-30.

10. Gurol-Urganci I, Cromwell DA, Edozien LC et al. Risk of placenta previa in second birth after first birth cesarean section: a population-based study and meta-analysis. BMC Pregnancy Childbirth. 2011;11(1): 95 .

11. Usta IM, Hobeika EM, Abu Musa AA et al. Placenta previa-accreta: risk factors and complications. Am J Obstet Gynecol. 2005;193(3);1045-9. 
12. Cieminski A1, Długołiecki F. Placenta previa accreta Ginekol Pol. 2004;75(12):919-25.

13. Farine D, Fox HE, Timor-Tritsch I. Vaginal ultrasound for ruling out placenta praevia. Case report. Br J Obstet Gynaecol. 1989;96(1):117-9.

14. Smith RS, Lauria MR, Comstock $\mathrm{CH}$, Treadwell MC, Kirk JS, Lee W, Bottoms SF. Transvaginal ultrasonography for all placentas that appear to be low-lying or over the internal cervical os. Ultrasound Obstet Gynecol. 1997;9(1):22-4.

Cite this article as: Sidhiq MC. Maternal and fetal outcome of Placenta Previa at a tertiary centre in North Kerala, India. Int J Reprod Contracept Obstet Gynecol 2018;7:1723-9. 